\title{
Managerial Delegation Contracts under Centralized Unionization ${ }^{\dagger}$
}

\author{
Nicola Meccheri ${ }^{\mathrm{a}, \mathrm{b},{ }^{*}}$ and Luciano Fanti ${ }^{\mathrm{a}}$ \\ ${ }^{a}$ Department of Economics and Management, University of Pisa, Pisa, Italy \\ ${ }^{\mathrm{b}}$ RCEA, The Rimini Centre for Economic Analysis, Rimini, Italy
}

Final version to be published on Managerial and Decision Economics:

February 7, 2013

\begin{abstract}
:
This paper studies how alternative managerial delegation contracts in a duopoly product market interact with wage decisions taken by a central (industry-wide) union in the labor market. Interestingly, results prove to be more varied with respect to findings by the managerial delegation literature with exogenous production costs. Most notably, it is pointed out that, in equilibrium, both firm profitability and welfare outcomes can be superior under both sales delegation and relative profit delegation, depending on various factors such as the degree of product differentiation and the competition regime.
\end{abstract}

JEL codes: J33, J51, L13

Keywords: sales delegation, relative profit delegation, unionized duopoly, endogenous wage

\footnotetext{
${ }^{\dagger}$ We would like to thank participants at SIE 2012 (Matera) for useful remarks. Usual disclaimers apply.

${ }^{*}$ Correspondence to: Department of Economics and Management, University of Pisa, Via C. Ridolfi 10, I56124 Pisa, Italy. E-mail: meccheri@ec.unipi.it
} 


\section{Introduction}

Since the seminal work by Berle and Means (1932), economists have recognized that in large companies ownership and control are separate, and managers may be driven not just by pure profit maximization, but also by, for example, sales maximization (e.g., Baumol, 1958). Furthermore, several works have considered the impact of manipulating managerial behavior in duopoly games by incentive contracts in order to attain a strategic advantage. Particularly, Fersthman (1985), Vickers (1985), Fersthman and Judd (1987) and Sklivas (1987) studied two-stage delegation games where, in the first stage, the firm's owner chooses an incentive scheme for the manager based on a linear combination of profits and sales and, in the second stage, the manager competes in an oligopoly game. Paradoxically, they show that under Cournot competition in the product market, owners will choose to put a positive weight on both profits and sales, in order to direct their managers to a more aggressive behavior in the market. ${ }^{1}$ Salas-Fumás (1992) and Miller and Pazgal (2001, 2002) considered the managerial delegation two-stage game but admit that, in the first stage, manager incentive schemes can be based on the weighted sum of the firm's profit and its rival's profit, that is, it can refer to relative profit (or performance). ${ }^{2}$ Their key result is that relative performance can be used as a strategic commitment device that can increase firm profits as opposed to a standard Cournot framework where firms directly choose output to maximize their own profits. More recent works (Jansen et al., 2009; van Witteloostuijn et al., 2007; Manasakis et al., 2010;

\footnotetext{
${ }^{1}$ Starting with Baker et al. (1988), Jensen and Murphy (1990) and Lambert et al. (1991), there have been a number of empirical studies confirming that CEO compensation is positively associated with both profits and sales.

${ }^{2}$ Empirical support for top executive compensation based on relative performance evaluation has been provided first by Gibbons and Murphy (1990), Barro and Barro (1990), Janakiraman et al. (1992) and Aggarwal and Samwick (1999).
} 
Jansen et al., 2012) compared the impact of sales delegation and relative performance incentive contracts on firm profits and market outcomes showing that, for a wide range of situations, firm owners are better off (i.e., profits are higher) with relative profit delegation, while the reverse holds true for consumers and society as a whole (i.e., consumer surplus and social welfare are higher under sales delegation).

Together with managerial delegation, another important feature that widely characterizes modern economies is that labor markets are often unionized. However, one salient dimension that differentiates unionization structures is the degree of wage setting centralization (Calmfors and Driffill, 1988; Freeman, 1988; Layard and Nickell, 1999; Flanagan, 1999). In industry, decentralized wage setting, involving firm-specific unions, is commonly contrasted with a completely centralized system, in which an industry-wide union sets a standard wage for the entire industry. In this respect, there are substantial differences between countries as well as industries and, as suggested by Booth (1995, p. 95), "[i]t appears to be an empirical regularity that imperfections in the labor market are correlated with imperfections in the product market".

Indeed, there are theoretical reasons as well as several empirical works suggesting that union power, as indicated by a combination of union density and centralization, is positively related to the degree of industrial concentration. This is because the characteristics of concentrated industries increase the likelihood of union success at an industry level as well as maintaining its monopolistic position over time (see, for example, Wallerstein, 1999 in addition to the seminal papers by Segal, 1964 and Weiss, 1966). A positive relationship between union power and industrial concentration is also consistent with the dominant (albeit not unanimous) view that wages tend to be higher in more 
concentrated industries (e.g., Blanchflower, 1986; Dickens and Katz, 1987; Belman, 1988). ${ }^{3}$ Belman (1988), for instance, showed that the elasticity of wages with respect to market concentration (concentration effect) is positive and much of the concentration effect is indirect, i.e. mediated through unionization. Finally, there are reasons why workers are organized in a single encompassing union when all firms in the industry recruit workers from an integrated labor market with a high degree of worker mobility (Horn and Wolinsky, 1988a).

In addition to its empirical relevance in concentrated industries (such as duopolies), a centralized wage setting system is also important from a theoretical viewpoint. Indeed, Dhillon and Petrakis (2002) maintained that under quite general conditions a well-known "wage rigidity result" applies: as long as negotiations are centralized at an industry level, wages are the same irrespectively of a wide range of product characteristics (i.e., the degree of product differentiation, the number of competing firms and the competition regime) as well as institutional features (i.e. bargaining over wages alone or over both wages and employment). ${ }^{4}$ However, by considering profit-maximizing firms in the product market, Dhillon and Petrakis (2002) do not tackle managerial delegation. Nonetheless, as discussed above, managerial delegation is an important institutional feature in real world markets. Thus it is worth extending their analysis in order to assess the impact of different managerial incentive schemes. Specifically, examining whether the "wage rigidity result" of Dhillon and Petrakis (2002) holds true even when firms delegate strategic decisions to managers, manipulating them through alternative incentive contracts, is relevant to the

\footnotetext{
${ }^{3}$ Starting with Rees (1977), there are also works that reject the idea that more concentrated industries will pay higher wages than less concentrated industries.

${ }^{4}$ The central monopoly union (common input monopoly supplier), considered in this work, is a limiting case (with union having all the bargaining power vis-à-vis firms) of such a situation, hence the wage rigidity result provided by Dhillon and Petrakis (2002) also clearly refers to this case.
} 
concerns of industrial organization, labor economics and management strategy.

This paper deals with this issue by considering a duopoly industry where strategic decisions are delegated by firm owners (or, alternatively, boards of directors) to managers, while the wages for non-managerial workers are uniform across firms since they are (strategically) set by a monopoly centralized (industry-wide) union. By developing a three-stage game framework, we bring together two different strands of the industrial organization literature: managerial delegation and the growing literature on unionized oligopolies (e.g., Horn and Wolinsky, 1988b; Dowrick, 1989; Naylor, 1999; Correa-López and Naylor, 2004; Lommerud et al., 2005; Correa-López, 2007; Symeonidis, 2010). In particular, we will study a basic framework where, in the first stage, firm' owners delegate strategic decisions and choose incentive contracts for managers; in the second stage, the union fixes the wage of all workers in the industry; and finally, in the third stage, managers compete in a Cournot framework. ${ }^{5}$

We then analyze how alternative managerial incentive schemes interact differently with the union's wage decision, as well as how this affects the equilibrium wage in the industry (this allows us to assess the generality in this context of the "wage rigidity result" by Dhillon and Petrakis, 2002), equilibrium profits and welfare outcomes (enabling us to compare our findings with those obtained by the previous literature on managerial delegation where firms' production costs are exogenously given). We will concentrate on managerial delegation under two alternative incentive contracts, namely sales delegation ( $\mathrm{S}$ contracts) and relative profit delegation (RP contracts). As

\footnotetext{
${ }^{5}$ Note that the union maximization problem parallels the one facing a profit maximizing upstream monopoly that is allowed to set the price of an input it supplies to downstream firms. Furthermore, while we provide our results in relation to the monopoly (central) union case, it is worth stressing that such results also hold true by continuity in a wage bargaining model, provided that the union bargaining power is sufficiently high (the monopoly union case is adopted in the unionized oligopoly literature by, e.g., Brekke, 2004 and Lommerud et al., 2005).
} 
already discussed, these schemes are particularly interesting in terms of their empirical relevance as well as their prominent role in the theoretical literature. ${ }^{6}$

Our results only partially confirm the received literature. Firstly, we show that under RP contracts, the equilibrium wage set by the central union does not depend on the weight chosen by the firm owners for the bonus payment to their managers. Furthermore, it exactly replicates that obtained under no-delegation, in which firms choose output to maximize profits. By contrast, the equilibrium wage under sales delegation depends on weights in managerial incentive contracts and is higher than the wage under RP contracts. Hence, the "wage rigidity result" only partially holds true in our framework: it remains valid if we compare the result obtained under RP contracts vis-àvis the result for the no-delegation case, but it no longer applies if we introduce $\mathrm{S}$ contracts into the analysis.

Secondly, in line with the results obtained in the literature, the introduction of managerial delegation, regardless of sales delegation or relative profit delegation, always penalizes profits but improves social welfare. Furthermore, profits are more strongly penalized under S contracts. However, while standard results suggest that overall welfare is higher with $\mathrm{S}$ than RP contracts, under centralized unionization (endogenous wage) the reverse applies.

\footnotetext{
${ }^{6}$ In a standard managerial delegation framework (i.e. with exogenous production costs), van Witteloostuijn et al. (2007) compare these schemes in a model with bargaining between owners and managers over managerial contracts. Note that we also adopt the terminology of van Witteloostuijn et al. (2007) (as well as Jansen et al. 2009): we refer to sales delegation in relation to schemes based on a combination of profits and output (see also Vickers, 1985). According to Fershtman and Judd (1987) and Sklivas (1987) on the other hand, sales delegation in other works also refers to a combination of profits and revenue. In addition, Jansen et al., (2007) propose a two-stage delegation model based on profits and market shares, and Jansen et al., (2009), Manasakis et al., (2010) and Jansen et al., (2012) compare such a scheme against sales delegation and relative profit delegation. We defer to future research the analysis in our (three-stage) unionized framework of the case with market shares delegation.
} 
We also extend the basic framework, where above results are initially derived, by introducing product differentiation under both Cournot and Bertrand competition. As Singh and Vives (1984) and Spulber (1989) originally pointed out, in differentiated products duopolies equilibrium outcomes generally depend on whether the firms compete in prices or quantities and on whether the goods are substitutes or complements. In our case, when firms compete in quantities, the unconventional result that overall welfare is always higher under RP contracts is confirmed. Instead, in terms of firms' profitability, results are more varied. Profits are larger (smaller) with RP contracts than without managerial delegation whenever products are complements (substitutes). We also obtain a novel result that when products are neither strong complements nor strong substitutes, the most preferred (i.e. profitable) incentive scheme by firms is sales delegation. This is linked to the fact that unless products are strong substitutes, the wage chosen by the union is lower when firms adopt $\mathrm{S}$ contracts.

When firms compete in terms of price, profits are larger (smaller) without managerial delegation than with RP contracts, whenever products are complements (substitutes). On the other hand, as in the case of quantity competition, if products are neither strong complements nor strong substitutes, firms make the highest profits by means of sales delegation. Social welfare as well as output (employment) and union utility are always higher without managerial delegation. However, when managerial delegation applies, sales delegation outperforms RP contracts in terms of overall efficiency, only when the degree of product substitutability is sufficiently high. ${ }^{7}$

\footnotetext{
${ }^{7}$ We also show that, under RP, Bertrand competition leads to exactly the same equilibrium outcomes as Cournot competition, which generalizes Miller and Pazgal's (2001) well-known "equivalence result" between competition modes under relative profit delegation to a three-stage delegation game with centralized unionization (endogenous production costs).
} 
Despite the huge increase in studies over the last two decades in the literature regarding managerial delegation and unionized oligopolies, cross-fertilization between such prominent strands of IO theory is still rare. Szymanski (1994) first extended the managerial delegation model by introducing wage bargaining between firm owners and firm-specific unions. His study showed that, with respect to the previous literature, owners set incentives closer to profit maximization than to sales maximization and that increasing union power may increase the profitability of the firm. On the other hand, Bughin (1995) considered a two-stage game, in which, in the first stage, wages are bargained between firms and unions and, in the second stage, output decisions are made cooperatively by the owner (who maximizes profits) and the manager (who maximizes sales). ${ }^{8}$

While both Szymanski (1994) and Bughin (1995) focus exclusively on decentralized modes of wage setting with firm-specific unions, in Fanti and Meccheri (2013) we consider also centralized unionization in order to assess the relative performance of alternative institutional wage setting regimes in a model with managerial delegation. ${ }^{9}$ In particular, we show the opposite role played by the introduction of managerial delegation according to the different unionization structure: while under an industry-wide union, managerial delegation leads to sale incentives, lower profits and higher consumer surplus as well as overall welfare, in the presence of decentralized (firm-specific) unions, all these results are reversed. In addition, we highlight that introducing managerial

\footnotetext{
${ }^{8}$ Recent studies tackle a related, but different issue, namely strategic delegation in wage bargaining. Mauleon and Vannetelbosch (2006) consider the possibility that surplus-maximizing unions delegate wage bargaining to wage-maximizing delegates (such as senior union members) and analyze how this affects incentives for mergers by firm owners. Liao (2010), instead, investigates the choice of a firm's delegate (either the owner or the manager) in bargaining wages and employment with a union under a unionized duopoly. Finally, Chatterjee and Saha (2011) provide a more general model with bilateral delegation, that is, one that encompasses the possibility of both firm and union delegation.

${ }^{9}$ Indeed, Szymanski himself recognized that analyzing the role of an industry wide union is an important issue that deserves further investigation (see, Szymanski, 1994, p. 114).
} 
delegation makes the unionization structure neutral in relation to consumer surplus and overall efficiency.

However, Szymanski (1994), Bughin (1995) and Fanti and Meccheri (2013) focus on sales delegation alone, while neglecting relative profit delegation. Thus, to the best of our knowledge, the present paper is the first work that studies relative profit delegation in a model with endogenous production costs and (central) unionization, by comparing results obtained under this type of managerial scheme against those related to sales delegation.

The rest of the paper is organized as follows. In Section 2, the basic framework is presented and a benchmark case is analyzed, in which firms do not delegate output decisions to managers (or, alternatively, delegate output decisions but use incentive contracts only based on profits). In Section 3 , we outline our main results in a three-stage game with centralized unionization and alternative managerial delegation schemes, namely S contracts and RP contracts. In Section 4, we extend these results to product differentiation and price competition. Finally, Section 5 presents the conclusions, and further details are provided in the appendix.

\section{The model}

\subsection{Basic framework}

We adopt a managerial delegation basic framework, which is partially modeled along the lines of van Witteloostuijn et al. (2007) and Jansen et al. (2009), where we introduce the presence of a centralized labor union in determining workers' wages. We consider a duopolistic market where 
two identical firms produce a homogeneous product and compete over quantities (Cournot). The inverse demand is given by:

$$
p(Q)=1-Q
$$

where $p$ denotes price and $Q$ is the sum of the output levels $q_{i}$ and $q_{j}$ produced by the two firms (with $i, j=1,2$ and $i \neq j$ ). ${ }^{10}$

Both firms use only labor to produce according to a production function with constant returns $q_{i}=L_{i}$, where $L_{i}$ represents the number of workers employed by firm $i$. The $i$-th firm faces an average and marginal cost $w_{i}<1$ for every unit of output produced so that its cost function is given by:

$$
C_{i}\left(q_{i}\right)=w_{i} L_{i}=w_{i} q_{i}
$$

while its profits, denoted by $\pi_{i}$, are:

$$
\pi_{i}=\left(p_{i}-w_{i}\right) q_{i}
$$

which, taking (1) into account, becomes $\pi_{i}=\left(1-Q-w_{i}\right) q_{i}$. We assume that $w_{i}$, the wage per unit of labor (i.e. the marginal cost), is unilaterally chosen by a centralized union, which fixes a uniform wage for the industry as a whole (i.e. $w_{i}=w_{j}=w$ ). The union's utility function is given by:

\footnotetext{
${ }^{10}$ Note that the standard model with inverse demand $p^{\prime}=a-b Q^{\prime}$ can be transformed into this normalized model simply by using $p=p^{\prime} / a$ and $Q=(b / a) Q^{\prime}$.
} 


$$
V=\left(w-w^{\circ}\right)\left(L_{i}+L_{j}\right)=\left(w-w^{\circ}\right) Q
$$

where $w^{\circ}$ is the reservation wage, that is, the wage that could be earned in the competitive sector of the economy. ${ }^{11}$ Note that this functional form encompasses both the case of a total wage bill maximizing union (with $w^{\circ}=0$ ) and that in which the union is rent-maximizing (when $w^{\circ}>0$ ). Remarkably, in the latter case, the union maximization problem is equivalent to the issue faced by a profit maximizing upstream monopoly that is allowed to set the price of a common input it supplies to downstream firms.

We assume that each firm's owner hires a manager and delegates the output decision to this manager. Each manager receives a fixed salary plus a bonus element, which is related to a weighted combination between firm profits and other performance measures. We consider two possible alternative incentive schemes including, together with profits, either the firm's own sales (S contracts) or the rival's profits (RP contracts), respectively (van Witteloostuijn et al., 2007; Jansen et al., 2009). Note that we assume that the nature of the remuneration scheme is exogenous in this context. For instance, as pointed out by Jansen et al. (2009, p. 142), this may be related to the fact that remuneration is determined by norms and rules specific to the country where both firms operate.

Formally, when firms adopt sales delegation, if firm $i$ 's profits are positive - otherwise there is no bonus - manager $i$ receives a bonus that is proportional to:

$$
u_{i}^{S}=\pi_{i}+b_{i}^{S} q_{i}=\left(1-Q-w+b_{i}^{S}\right) q_{i}
$$

\footnotetext{
${ }^{11}$ This is a specific case of the more general Stone-Geary utility function (e.g., Pencavel, 1984, 1985; Mezzetti and Dinopoulos, 1991; Dowrick and Spencer, 1994; Petrakis and Vlassis, 2000).
} 
where $b_{i}^{S}$ is the incentive parameter that is chosen by firm $i$ 's owner and may be either positive or negative depending on whether the owner provides incentives or disincentives to the manager's choice of output (sales). ${ }^{12}$ Specifically, if $b_{i}^{S} \neq 0$, the firm $i$ 's manager moves away from strict profit-maximization towards including the consideration of sales. This implies that he/she becomes a more $\left(b_{i}^{S}>0\right)$ or less $\left(b_{i}^{S}<0\right)$ aggressive seller in the market.

Under relative profit delegation, instead, a manager $i$ receives a bonus that is proportional to:

$$
u_{i}^{R P}=\pi_{i}-b_{i}^{R P} \pi_{j}=(1-Q-w)\left(q_{i}-b_{i}^{R P} q_{j}\right)
$$

where $b_{i}^{R P}$ can be either positive or negative, so that similar considerations as for $b_{i}^{S}$ apply: when $b_{i}^{R P}>0$, the firm becomes more aggressive, putting more weight on profit differences; conversely, when $b_{i}^{R P}<0$, the firm becomes more "cooperative". However, as pointed out by Miller and Pazgal (2002, p. 55), since $\left|b_{i}^{R P}\right|>1$ would imply that the manager is more concerned with his/her rival than with the performance of his/her own firm, and it is reasonable to believe that managers do not actually behave in this manner, in what follows we will assume and focus on the case with $b_{i}^{R P} \in(-$ $1,1)^{13}$

\footnotetext{
${ }^{12} \mathrm{We}$ also follow the standard assumption of the managerial delegation theory that the fixed component (salary) of the manager's compensation is chosen by the firm's owner, so that the manager gets exactly his/her opportunity cost, which is normalized to zero (see, Miller and Pazgal, 2002 for an alternative interpretation).

${ }^{13}$ There are another two points of interest. First, note that (6) is equivalent to $\left(1-b_{i}^{R P}\right) \pi_{i}+b_{i}^{R P}\left(\pi_{i}-\pi_{j}\right)$. Secondly, passing from (6) to $\pi_{i}+b_{i}^{R P^{\prime}}\left(\pi_{i}-\pi_{j}\right)$, whose form is more in line with (5), is straightforward. This can be done by means of $b_{i}^{R P \prime}=b_{i}^{R P} /\left(1-b_{i}^{R P}\right)$, according to which, for $b_{i}^{R P} \in(-1,1), b_{i}^{R P}$ and $b_{i}^{R P}$ maintain the same qualitative properties (i.e. the sign). More importantly, equilibrium market outcomes under relative
} 


\subsection{A benchmark case}

For the following comparisons and discussion, it is useful to derive, in our "unionized" framework, the equilibrium outcomes for profit-maximizing firms, that is, when firms do not delegate output decisions to managers. This can also be interpreted as owners delegating decisions to their managers and using incentive contracts based on pure profits only (PP contracts).

To derive equilibrium results for this two-stage game, where in the first stage the union fixes the wages, while in the second stage, the output is chosen to maximize profits, we consider that firm $i$ maximizes (3) with respect to $q_{i}$, taking $q_{j}$ and $w$ as given. This leads to the following reaction function in output space:

$$
q_{i}\left(q_{j}, w\right)=\frac{1-q_{j}-w}{2}
$$

From (7) and its counterpart for firm $j$ we can obtain firm $i$ 's output for given $w$ as:

$$
q_{i}(w)=\frac{1-w}{3} .
$$

By substituting (8) in (4) and maximizing with respect to $w$, we get the following equilibrium value for the wage, where the subscript $P P$ refers to the "pure profits" (or no-delegation) case:

profit delegation, which are involved in our comparisons with the sales delegation, are exactly the same using (6), which is what we do in what follows (in line with Jansen et al., 2009), or instead the alternative expression with $b_{i}^{R P}$. 
(9)

$$
w^{P P^{*}}=\frac{1}{2} \alpha
$$

where $\alpha \equiv 1+w^{\circ}$. By substituting in (8) and (3), we also get the following results for equilibrium output and profits, respectively:

$$
q^{P P^{*}}=\frac{1}{6} \beta ; \quad \pi^{P P^{*}}=\frac{1}{36} \beta^{2}
$$

where $\beta \equiv 1-w^{\circ}$. Finally, taking (4) into account and considering that, in the Cournot equilibrium, consumer surplus is generically given by $C S=2 q^{2}$ and overall welfare is $W=C S+2 \pi+V$, the following results define welfare outcomes for this case:

$$
V^{P P^{*}}=\frac{1}{6} \beta^{2} ; \quad C S^{P P^{*}}=\frac{1}{18} \beta^{2} ; \quad W^{P P^{*}}=\frac{5}{18} \beta^{2} .
$$

\section{The three-stage delegation game}

We consider now a three-stage game, in which firms delegate output decisions to managers, while workers' wages are fixed by an industry-wide union. The specific sequence of moves for this game is as follows: 

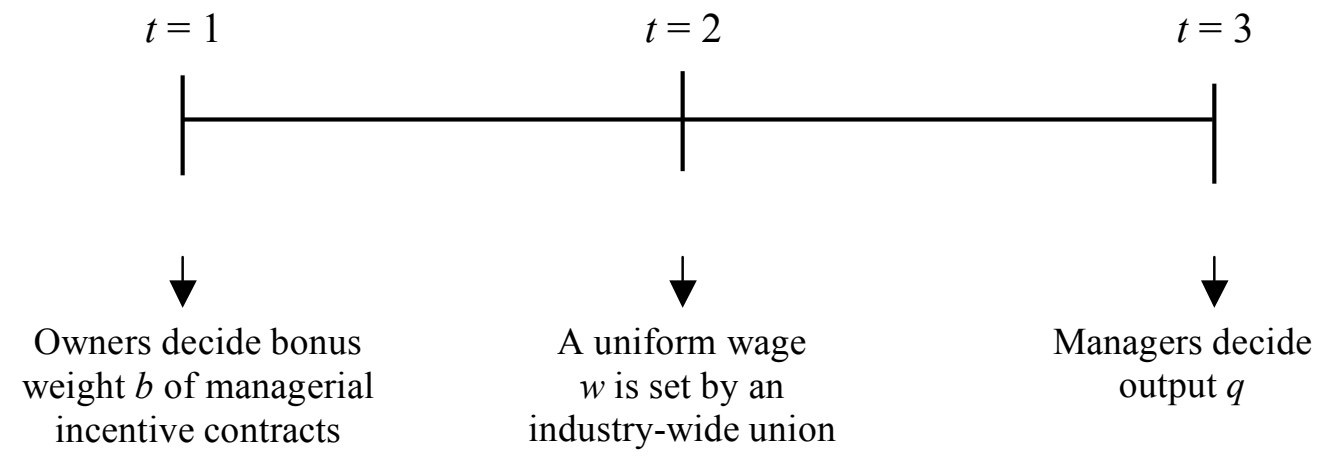

Fig. 1. Sequence of moves

As usual, the game is solved by backward induction. We proceed with the analysis in accordance with the different managerial bonus structure provided by the owners for their managers, starting with the $\mathrm{S}$ contract case.

\subsection{S contracts}

In the third stage, firm $i$ 's manager maximizes (5) with respect to $q_{i}$, leading to the following reaction function:

$$
q_{i}\left(q_{j}, w, b_{i}\right)=\frac{1-q_{j}-w+b_{i}}{2}
$$

From (12) it is easy to argue that $w-b_{i}$ may be thought as the marginal cost of production for the manager, so that the manager considers that this marginal cost is lower than the one for the 
owner in the benchmark case without delegation. ${ }^{14}$ As a consequence, the lower the managerial incentive parameter set by owner $i$, the higher the aggressiveness of the manager and the higher the output level chosen by him/her. Furthermore, from (12) and its counterpart for firm $j$, we obtain firm $i$ 's output for given $w, b_{i}$ and $b_{j}$ :

$$
q_{i}\left(w, b_{i}, b_{j}\right)=\frac{1-w+2 b_{i}-b_{j}}{3}
$$

After substitution of (13), in the second stage, union maximizes (4) with respect to $w$, which leads to:

$$
w\left(b_{i}, b_{j}\right)=\frac{2 \alpha+b_{i}+b_{j}}{4} .
$$

Note that the unionized wage positively depends on the weights placed by the owners on sales. This "wage effect" is due to the fact that, in equilibrium, output (and employment) clearly increases with the weights on sales. In turn, this drives the central union to increase its wage claim. By substituting in (3), we get profits as a function of the weight on sales only:

$$
\pi_{i}\left(b_{i}, b_{j}\right)=\frac{\left(2 \beta+7 b_{i}-5 b_{j}\right)\left(2 \beta-5 b_{i}-5 b_{j}\right)}{144} .
$$

\footnotetext{
${ }^{14}$ As known (Fershtman and Judd, 1987; Sklivas, 1987), from (12) it is also easy to observe that the Scompensated manager's reaction curve is an outward and parallel shift of the respective curve in the benchmark case.
} 
Now we are in a position to determine the optimal weights on sales. In the first stage, each owner simultaneously chooses $b$, the weight through which the manager is forced to give the desired quantity, with the Nash equilibrium describing the outcome. In this game between owners, each of them knows the profits of each possible third and second-stage game as a function of $b_{i}$ and $b_{j}$, as given by (15). By maximizing (15) with respect to $b_{i}$, we get the reaction function for an owner's choice of $b_{i}$ with respect to $b_{j}$ as:

$$
b_{i}\left(b_{j}\right)=\frac{2 \beta-5 b_{j}}{35}
$$

and, in symmetric equilibrium $\left(b_{i}=b_{j}=b\right)$, we get:

$$
b^{S^{*}}=\frac{1}{20} \beta
$$

where the subscript $S$ refers to the "sales delegation". Finally, by substituting for (17), we find the equilibrium results in relation to the wage rate, output and profits, respectively:

$$
w^{S^{*}}=\frac{1}{20}+\frac{19}{40} \alpha ; \quad q^{S^{*}}=\frac{7}{40} \beta ; \quad \pi^{S^{*}}=\frac{7}{320} \beta^{2}
$$

as well as the following welfare outcomes:

$$
V^{S^{*}}=\frac{147}{800} \beta^{2} ; \quad C S^{S^{*}}=\frac{49}{800} \beta^{2} ; \quad W^{S^{*}}=\frac{231}{800} \beta^{2} .
$$




\subsection{RP contracts}

Under RP contracts, in the third stage, each manager maximizes (6) with respect to the output, leading to the following reaction function:

$$
q_{i}\left(q_{j}, w, b_{i}\right)=\frac{1-q_{j}\left(1-b_{i}\right)-w}{2}
$$

From (20) we can observe that the reaction curve of the RP-compensated manager implies that he/she considers $-q_{j}\left(1-b_{i}\right)$ as the rival manager's best response. Hence, the rival's best response anticipated by the RP-compensated manager is lower than for an owner in the standard pure-profits or no-delegation case. ${ }^{15}$ Therefore the RP-compensated manager (as well as the Scompensated one) also sets the output at a higher level than a firm's owner. From (20) and its counterpart for $j$, we obtain output by firm $i$, for given $w, b_{i}$ and $b_{j}$ as:

$$
q_{i}\left(w, b_{i}, b_{j}\right)=\frac{(1-w)\left(1+b_{i}\right)}{3+b_{i}+b_{j}\left(1-b_{i}\right)}
$$

After the substitution of (21) and the corresponding expression for $j$, the union unilaterally chooses a uniform wage at the second stage of the game by maximizing (4), which leads to:

\footnotetext{
${ }^{15}$ In the RP case, the manager's reaction curve (20) is a rotation through the intercept of the corresponding one in the benchmark (no-delegation) case (Miller and Pazgal, 2002).
} 


$$
w^{R P^{*}}=\frac{1}{2} \alpha .
$$

Two aspects are worth highlighting in relation to (22), which are stated in the following lemma.

Lemma 1. Under relative profit delegation, the equilibrium wage set by a central union is independent of the bonus weights chosen by the owners for their managers. Furthermore, this is in contrast with what applies under sales delegation (see (14)).

By substituting in the profit equation (3), we get:

$$
\pi_{i}\left(b_{i}, b_{j}\right)=\frac{(2-\alpha)^{2}\left(1+b_{i}\right)\left(1-b_{i} b_{j}\right)}{4\left[3+b_{i}+b_{j}\left(1-b_{i}\right)\right]^{2}}
$$

and solving for the optimal bonus weight for manager yields the following reaction function in bonus weights space:

$$
b_{i}\left(b_{j}\right)=\frac{1-b_{j}}{1+3 b_{j}} .
$$

As pointed out by Miller and Pazgal (2002), reaction functions as defined by (24) imply a continuum of equilibria. However, in the standard two-stage delegation game, along the overlapping reaction curves aggregate industry profits and output are constant, with a different 
distribution between the two firms. ${ }^{16}$ In addition, for all possible solutions of the delegation (first) stage, there is just one solution for the product market (second) stage. In our three-stage game, since the equilibrium wage chosen by the union in the second stage does not depend on bonus weights (see Lemma 1), all the above outcomes of the standard (two-stage) relative profit delegation game remain true. Thus, our findings extend the indeterminacy result obtained by Miller and Pazgal (2002) to the three-stage game with the managerial delegation and unionized duopoly.

In accordance with the literature (e.g., Miller and Pazgal, 2002), we concentrate on the unique symmetric equilibrium $\left(b_{i}=b_{j}=b\right)$ of the first-stage game, which is:

$$
b^{R P^{*}}=\frac{1}{3}
$$

This leads to the following outcomes for output, profits and welfare:

$$
\begin{aligned}
& q^{R P^{*}}=\frac{3}{16} \beta ; \quad \pi^{R P^{*}}=\frac{3}{128} \beta^{2} \\
& V^{R P^{*}}=\frac{3}{16} \beta^{2} ; \quad C S^{R P^{*}}=\frac{9}{128} \beta^{2} ; \quad W^{R P^{*}}=\frac{39}{128} \beta^{2} .
\end{aligned}
$$

\footnotetext{
${ }^{16}$ The equilibrium pairs at the extremes of the reaction function entail an output level that replicates the outcome of a Stackelberg model, in which one of the firms takes the role of leader or follower (Miller and Pazgal, 2002).
} 


\subsection{Outcome comparison}

In this section we compare the outcomes obtained above under alternative bonus schemes for managers. Moreover, in order to get a better understanding of our results, it is worth highlighting the following remark (see also the discussion of the literature in the Introduction).

Remark. From the literature on managerial delegation with exogenous production costs, we know that, under alternative bonus schemes, the following rankings apply (e.g., Jansen et al., 2009):

$$
q^{S}>q^{R P}>q^{P P} ; \pi^{P P}>\pi^{R P}>\pi^{S} ; W^{S}>W^{R P}>W^{P P} .
$$

Now we can turn to our results and, firstly, state the following lemma, which summarizes the ranking of the equilibrium outcomes (including those related to the pure-profit, or no-delegation, case presented in Section 2.2 as a benchmark) in our context.

Lemma 2. In a managerial delegation game in which the wage is set by a central union, by means of a simple comparison of the equilibrium results obtained above, we can state the following rankings for output, profits, wage, union utility and overall welfare:

$$
q^{R P^{*}}>q^{S^{*}}>q^{P P^{*}} ; \pi^{P P^{*}}>\pi^{R P^{*}}>\pi^{S^{*}} ; w^{S^{*}}>w^{P P^{*}}=w^{R P^{*}} ; V^{R P^{*}}>V^{S^{*}}>V^{P P^{*}} ; W^{R P^{*}}>W^{S^{*}}>W^{P P^{*}} .
$$

From the rankings of Lemma 2, and by comparing them with those recalled in the Remark above (the "standard results"), the following outcomes are derived. 
Result 1. In an economy with an industry-wide (monopoly) union, the following statements hold true:

i) in line with standard results, regardless of whether the managerial bonus structure is $S$ or RP, the introduction of managerial delegation (that is, shifting from the PP case) always penalizes profits but improves overall welfare. However, while standard results suggest that overall welfare is higher under sales delegation than under relative profit delegation, the reverse applies with centralized unionization;

ii) the equilibrium wage chosen under managerial delegation and RP contracts exactly replicates that obtained under no-delegation, in which firms choose output to maximize (pure) profits. By contrast, the equilibrium wage under sales delegation is higher;

iii) the rankings of wages and employment under $S$ and RP incentives are at odds. However, union utility as a whole is higher under relative profit delegation.

It is important to stress the crucial role played by the presence of a union in "reversing" the standard result that sales delegation always leads to higher output and, as a consequence, to larger consumer surplus and also overall welfare. Indeed, the result (confirmed here) that under sales delegation, owners choose to put a positive weight on sales, making their managers more aggressive in the product market, leads to another important consequence. As already remarked, it also leads the central union to increase its wage claim. This "wage effect" is absent in a standard managerial 
delegation model without unionization, where wages are assumed to be exogenously given. Also, we have shown that, even when unionization is introduced into the analysis, such an effect does not apply when firms adopt RP contracts. This is because, in this case, the wage chosen in equilibrium by the union does not depend on the bonus weight (Lemma 1).

Clearly, the wage effect in turn operates against the positive effect played by the bonus on sales. The final outcome is that the equilibrium output is even lower under $\mathrm{S}$ contracts in comparison with relative profit delegation. Furthermore, since wages are higher under sales delegation, the standard result that RP contracts lead to higher profits is confirmed (and even strengthened) in this context. Finally, even when faced with a wage-employment trade-off, in the end unions also prefer RP to S contracts. All of this unambiguously implies that overall welfare is lower with sales delegation than with relative profit delegation.

\section{$4 \quad$ Extensions}

\subsection{Product differentiation}

In this section we extend the previous analysis to the case in which firms still compete in a Cournot framework but with differentiated products. We assume that each firm $i$ is faced with the following (inverse) demand function, which replaces (1) in the analysis:

$$
p_{i}\left(q_{i}, q_{j}\right)=1-q_{i}-\gamma q_{j}
$$


where $\gamma \in(-1,1)$ represents the degree of product differentiation. Specifically when $-1<\gamma<0$ products are complements (the higher $|\gamma|$, the higher the degree of complementarity), for $0<\gamma<1$ products are substitutes (the higher $\gamma$, the higher the degree of substitutability), while for $\gamma=0$ they are independent.

In this context, the following outcomes, related to the different cases studied in the previous section, apply in equilibrium (see Section A.1 in the appendix for derivations).

(29) PP contracts:

$$
\bar{w}^{P P^{*}}=\frac{1}{2} \alpha ; \bar{q}^{P P^{*}}=\frac{1}{2(2+\gamma)} \beta ; \bar{\pi}^{P P^{*}}=\frac{1}{4(2+\gamma)^{2}} \beta^{2} ; \bar{V}^{P P^{*}}=\frac{1}{2(2+\gamma)} \beta^{2} ; \quad \bar{W}^{P P^{*}}=\frac{7+3 \gamma}{4(2+\gamma)^{2}} \beta^{2}
$$

(30) S contracts: $\left(A \equiv 14-\gamma^{2}+7 \gamma\right)$

$$
\begin{gathered}
\bar{b}^{S^{*}}=\frac{2 \gamma^{2}+\gamma-2}{A} \beta ; \quad \bar{w}^{S^{*}}=\frac{1}{2} \alpha+\frac{2 \gamma^{2}+\gamma-2}{2 A} \beta ; \quad \bar{q}^{S^{*}}=\frac{6+\gamma}{2 A} \beta ; \quad \bar{\pi}^{S^{*}}=\frac{(6+\gamma)\left(10-4 \gamma^{2}-\gamma\right)}{4 A^{2}} \beta^{2} \\
\bar{V}^{S^{*}}=\frac{(6+\gamma)\left(12+\gamma^{2}+8 \gamma\right)}{2 A^{2}} \beta^{2} ; \bar{W}^{S^{*}}=\frac{(6+\gamma)\left(50-5 \gamma^{2}+21 \gamma\right)}{4 A^{2}} \beta^{2}
\end{gathered}
$$

\section{RP contracts:}

$$
\begin{gathered}
\bar{b}^{R P^{*}}=\frac{\gamma}{2+\gamma} ; \quad \bar{w}^{R P^{*}}=\frac{1}{2} \alpha ; \quad \bar{q}^{R P^{*}}=\frac{2+\gamma}{8(1+\gamma)} \beta ; \quad \bar{\pi}^{R P^{*}}=\frac{(2+\gamma)(2-\gamma)}{64(1+\gamma)} \beta^{2} ; \\
\bar{V}^{R P^{*}}=\frac{2+\gamma}{8(1+\gamma)} \beta^{2} ; \bar{W}^{R P^{*}}=\frac{(2+\gamma)(14-\gamma)}{64(1+\gamma)} \beta^{2} .
\end{gathered}
$$

From the outcomes summarized above, the following observations can be made. Firstly, with reference to the optimal bonus weight $b$, we get: 


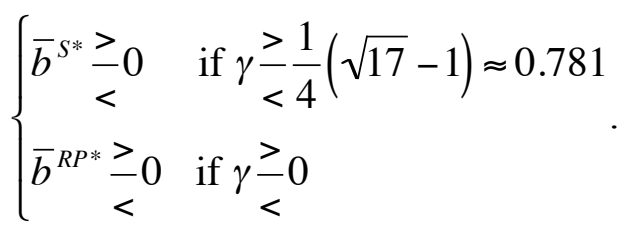

Under S contracts, firms are more aggressive only when products are sufficiently close substitutes. Otherwise, owners prefer to penalize managers for sales, making them less aggressive than their rivals. This contrasts with previous works that suggested that under sales delegation the weight placed by owners on sales is always positive whenever firms compete in quantities and goods are (perfect or imperfect) substitutes. ${ }^{17}$

In our framework, however, this different result makes sense. Indeed, we know from Section 3 that two distinct effects influence the weight on sales: the (standard) "competition effect" and the "wage effect". Furthermore, when products are perfect substitutes, the former outweighs the latter since, in equilibrium, the bonus is positive, that is, the conventional result applies (see (17) above). By contrast, when the degree substitutability between products (hence, the degree of strategic interaction/competition between firms) is very low, the (positive) role played by the competition effect tends to vanish. Thus, unless goods are close substitutes, the (negative) wage effect will prevail and, in equilibrium, owners will decide to penalize managers for sales.

Under RP contracts, on the other hand, the sign of $b$ parallels exactly the sign of $\gamma$, i.e., firms are less (more) aggressive when products are complements (substitutes), which is in line with previous results on managerial delegation with exogenous costs (see, in particular, Miller and

\footnotetext{
${ }^{17}$ For instance, as pointed out by Fershtman and Judd (1987, fn 7) "[h]ad we assumed our differentiated producers competed in quantities, then the results would have resembled those of the non-differentiated Cournot analysis".
} 
Pazgal, 2002). This is mainly due to the fact that, since under RP contracts, the equilibrium wage is independent of the weight on the rival's profit (see Appendix, Section A.1), no "wage effect" applies in this case.

Secondly (and more importantly), in relation to the optimal wage chosen by the central union, we obtain that:

$$
\begin{cases}\bar{w}^{R P^{*}}=\bar{w}^{P P^{*}}>\bar{w}^{S^{*}} & \text { if } \gamma<0.781 \\ \bar{w}^{S^{*}}>\bar{w}^{R P^{*}}=\bar{w}^{P P^{*}} & \text { otherwise }\end{cases}
$$

thus, unless products are strict substitutes, the union fixes a higher wage when firms adopt RP instead of S incentive contracts. Furthermore, while under PP and RP contracts (in line with Dhillon and Petrakis' (2002) "wage rigidity result") the equilibrium wage is independent of the degree of product differentiation, when owners adopt $\mathrm{S}$ incentive schemes we have instead that:

$$
\frac{\partial \bar{w}^{S^{*}}}{\partial \gamma} \frac{>}{<} 0 \Leftrightarrow 15 \gamma^{2}+52 \gamma+28 \underset{<}{\stackrel{>}{<}} 0 \Leftrightarrow \gamma \frac{>}{<}-\frac{2}{3}
$$

that is, except for the case when products are strong complements, the wage chosen by the central union increases with $\gamma$. In other words, unless products are strong complements (for which the wage decreases when the degree of complementarity decreases), the wage increases when the degree of complementarity between products decreases and the degree of substitutability increases.

Finally, in relation to the other key outcomes, we get: 


$$
\begin{aligned}
& \left\{\begin{array}{ll}
\bar{\pi}^{R *}>\bar{\pi}^{P P^{*}}>\bar{\pi}^{S^{*}} & \text { if } \gamma<-0.884 \\
\bar{\pi}^{R P^{*}}>\bar{\pi}^{S^{*}}>\bar{\pi}^{P P^{*}} & \text { if }-0.884<\gamma<-0.575 \\
\bar{\pi}^{S^{*}}>\bar{\pi}^{R P^{*}}>\bar{\pi}^{P P^{*}} & \text { if }-0.575<\gamma<0 \\
\bar{\pi}^{S^{*}}>\bar{\pi}^{P P^{*}}>\bar{\pi}^{R P^{*}} & \text { if } 0<\gamma<0.781 \\
\bar{\pi}^{P P^{*}}>\bar{\pi}^{S^{*}}>\bar{\pi}^{R P^{*}} & \text { if } 0.781<\gamma<0.92 \\
\bar{\pi}^{P P^{*}}>\bar{\pi}^{R P^{*}}>\bar{\pi}^{S^{*}} & \text { if } \gamma>0.92
\end{array} \quad ; \quad\left\{\begin{array}{l}
\bar{q}^{R P^{*}}>\bar{q}^{P P^{*}}>\bar{q}^{S^{*}} \quad \text { if } \gamma<0.781 \\
\bar{q}^{R P^{*}}>\bar{q}^{S^{*}}>\bar{q}^{P P^{*}} \quad \text { otherwise }
\end{array}\right.\right.
\end{aligned}
$$

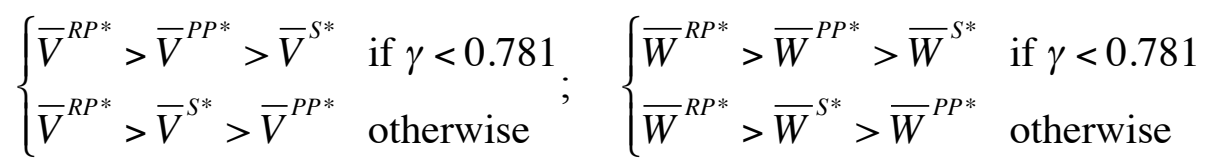

according to which the following result can be stated.

Result 2. In an economy with an industry-wide (monopoly) union and product differentiation (complements or substitutes), the following statements apply:

i) in relation to the profitability of alternative incentive schemes, results are mixed. Profits are larger (smaller) with RP contracts than without managerial delegation (or PP contracts) whenever products are complements (substitutes). However, if products are neither strong complements nor strong substitutes, firms make the highest profits through sales delegation;

ii) overall welfare, such as output (employment) and union utility, is always higher under $R P$ contracts than under both $S$ and PP contracts.

In relation to the comparison between results with RP contracts and the no-delegation (or PP contracts) case, note that part i) of the above result is in line with the literature (see, in particular, 
Miller and Pazgal, 2002). Obviously, this relates to the fact that, in such cases, the wage fixed by the central union is independent of the extent of product differentiation and, importantly, is always the same. Thus standard outcomes necessarily still apply.

By contrast, the possibility for firms to make the highest profits with sales delegation represents a novel result. Clearly, this is due to the fact that (unless products are close substitutes) the wage chosen by the union is lower when firms adopt S contracts. Furthermore, part ii) of Result 2 confirms that the unconventional result of Section 3, namely overall welfare is higher under relative profit delegation, holds true even if products are differentiated (complements or substitutes). ${ }^{18}$ Partly related to this, it is also worth noting that, when products are sufficient complements $(\gamma<-$ 0.575), shifting to RP contracts is Pareto improving, that is, agents involved (firms, union/workers and consumers) all prefer RP contracts to the other "delegation solutions" considered here. ${ }^{19}$

\subsection{Price competition}

Now, we consider a model of differentiated duopoly where firms compete in prices i.e. a Bertrand model. From (28) and its counterpart for firm $j$, we can write firm $i$ 's product demand as:

\footnotetext{
${ }^{18}$ In a framework with product differentiation (substitutes only) and managerial delegation, but without unions (i.e. exogenous production costs), Manasakis et al., (2010) show that overall welfare is always higher under revenue delegation than relative profit delegation. Although they do not consider output delegation explicitly, their results should imply a fortiori that the latter is always preferable to relative profit delegation from an overall efficiency viewpoint.

${ }^{19}$ Recall that, by assumption (see fn 13), managers are always constrained to their reservation utility, hence they show no particular preference for one specific delegation scheme.
} 


$$
q_{i}\left(p_{i}, p_{j}\right)=\frac{1-p_{i}-\gamma\left(1-p_{j}\right)}{1-\gamma^{2}}
$$

In this context, the following equilibrium outcomes apply (see Section A.2 in the appendix for derivations):

\section{PP contracts:}

$$
\begin{gathered}
\bar{w}_{B}^{P P^{*}}=\frac{1}{2} \alpha ; \bar{q}_{B}^{P P^{*}}=\frac{1}{2(2-\gamma)(1+\gamma)} \beta ; \bar{\pi}_{B}^{P P^{*}}=\frac{1-\gamma}{4(2-\gamma)^{2}(1+\gamma)} \beta^{2} ; \\
\bar{V}_{B}^{P P^{*}}=\frac{1}{2(2-\gamma)(1+\gamma)} \beta^{2} ; \quad \bar{W}_{B}^{P P^{*}}=\frac{7-4 \gamma}{4(2-\gamma)^{2}(1+\gamma)} \beta^{2}
\end{gathered}
$$

(38) S contracts: $\left(B \equiv 14+2 \gamma^{3}-5 \gamma^{2}-7 \gamma\right)$

$$
\begin{gathered}
\bar{b}_{B}^{S^{*}}=\frac{(\gamma-1)\left(\gamma^{2}-\gamma+2\right)}{B} \beta ; \quad \bar{w}_{B}^{S^{*}}=\frac{1}{2} \alpha+\frac{(\gamma-1)\left(\gamma^{2}-\gamma+2\right)}{2 B} \beta ; \quad \bar{q}_{B}^{S^{*}}=\frac{6-3 \gamma^{2}+\gamma}{2 B(1+\gamma)} \beta ; \\
\bar{\pi}_{B}^{S^{*}}=\frac{\left(6-3 \gamma^{2}+\gamma\right)\left(10+\gamma^{3}-11 \gamma\right)}{4 B^{2}(1+\gamma)} \beta^{2} ; \quad \bar{V}_{B}^{S^{*}}=\frac{\left(6-3 \gamma^{2}+\gamma\right)^{2}(2-\gamma)}{2 B^{2}(1+\gamma)} \beta^{2} ; \\
\bar{W}_{B}^{S^{*}}=\frac{\left(6-3 \gamma^{2}+\gamma\right)\left(50+8 \gamma^{3}-17 \gamma^{2}-29 \gamma\right)}{4 B^{2}(1+\gamma)} \beta^{2}
\end{gathered}
$$

\section{(39) RP contracts:}

$$
\bar{b}_{B}^{R P^{*}}=\frac{\gamma}{\gamma-2} ; \quad \bar{w}_{B}^{R P^{*}}=\bar{w}^{R P^{*}} ; \quad \bar{q}_{B}^{R P^{*}}=\bar{q}^{R P^{*}} ; \quad \bar{\pi}_{B}^{R P^{*}}=\bar{\pi}^{R P^{*}} ; \quad \bar{V}_{B}^{R P^{*}}=\bar{V}^{R P^{*}} ; \quad \bar{W}_{B}^{R P^{*}}=\bar{W}^{R P^{*}}
$$

From the outcomes summarised above, the following observations can be made. Firstly, note that, under RP contracts, the market outcomes with quantity and price competition are the same. 
This finding generalizes Miller and Pazgal's (2001) “equivalence result” to a three-stage delegation game with centralized unionization (endogenous production costs): in a duopoly delegation game, if owners have sufficient control over their managers' incentives, such as with an RP incentive scheme, then equilibrium outcomes will be the same regardless of whether managers compete in terms of price or quantity.

Furthermore, in relation to the optimal bonus weight $b$, we get:

$$
\left\{\begin{array}{cc}
\bar{b}_{B}^{S^{*}}<0 & \text { for any } \gamma \\
\bar{b}_{B}^{R P^{*}} \stackrel{\geq}{<} & \text { if } \gamma \leq 0 \\
> & <
\end{array}\right.
$$

which perfectly replicate, for this case, the results obtained by the literature without unionization (Fersthman and Judd, 1987; Sklivas, 1987; Miller and Pazgal, 2002). Under S contracts, owners penalize managers for sales. Thus managers that compete in terms of price behave less aggressively, which also implies that equilibrium prices are higher than in the Bertrand model with profitmaximizing firms (or PP contracts). Instead, under RP contracts, the results obtained under Cournot competition (see Section 4.1) are reversed when competition is in terms of price: managers become more (less) aggressive when products are complements (substitutes).

In relation to the equilibrium wage, we find (in line with the "wage rigidity result" prediction) that wages under PP and RP contracts replicate those obtained under Cournot competition with both homogenous and differentiated products. Instead, the equilibrium wage with $\mathrm{S}$ contracts depends on the degree of product differentiation and, more exactly, always increases 
with $\gamma \cdot{ }^{20}$ Moreover, with respect to RP (or PP) contracts, the wage chosen in equilibrium by the central union under S contracts is always lower.

Finally, from the above findings we derive the following rankings in relation to key variables:

$$
\begin{aligned}
& \left\{\begin{array}{ll}
\bar{\pi}_{B}^{P P^{*}}>\bar{\pi}_{B}^{S^{*}}>\bar{\pi}_{B}^{R P^{*}} & \text { if } \gamma<-0.936 \\
\bar{\pi}_{B}^{S^{*}}>\bar{\pi}_{B}^{P P^{*}}>\bar{\pi}_{B}^{R P^{*}} & \text { if }-0.936<\gamma<0 \\
\bar{\pi}_{B}^{S^{*}}>\bar{\pi}_{B}^{R P^{*}}>\bar{\pi}_{B}^{P P^{*}} & \text { if } 0<\gamma<0.812 \\
\bar{\pi}_{B}^{R P^{*}}>\bar{\pi}_{B}^{S^{*}}>\bar{\pi}_{B}^{P P^{*}} & \text { if } \gamma>0.812
\end{array} ;\left\{\begin{array}{ll}
\bar{V}_{B}^{P P^{*}}>\bar{V}_{B}^{R P^{*}}>\bar{V}_{B}^{S^{*}} & \text { if } \gamma<0.732 \\
\bar{V}_{B}^{P P^{*}}>\bar{V}_{B}^{S^{*}}>\bar{V}_{B}^{R P^{*}} & \text { otherwise }
\end{array} ;\right.\right. \\
& \left\{\begin{array}{ll}
\bar{q}_{B}^{P P^{*}}>\bar{q}_{B}^{R P^{*}}>\bar{q}_{B}^{S^{*}} & \text { if } \gamma<0.583 \\
\bar{q}_{B}^{P P^{*}}>\bar{q}_{B}^{S^{*}}>\bar{q}_{B}^{R P^{*}} & \text { otherwise }
\end{array} ; \begin{cases}\bar{W}_{B}^{P P^{*}}>\bar{W}_{B}^{R P^{*}}>\bar{W}_{B}^{S^{*}} & \text { if } \gamma<0.583 \\
\bar{W}_{B}^{P P^{*}}>\bar{W}_{B}^{S^{*}}>\bar{W}_{B}^{R P^{*}} & \text { otherwise }\end{cases} \right.
\end{aligned}
$$

Result 3. In an economy with an industry-wide (monopoly) union, product differentiation (complements or substitutes) and price competition, the following statements hold true:

i) in contrast with the results obtained under Cournot competition, profits are larger (smaller) without managerial delegation (or PP contracts) than with RP contracts whenever products are complements (substitutes). Instead, with respect to Cournot competition, our results confirm that if products are neither strong complements nor strong substitutes, firms make the highest profits through sales delegation;

\footnotetext{
${ }^{20}$ By differentiating with respect to $\gamma$ the equilibrium wage under sales delegation and Bertrand competition (as defined above in (39)), we get that $\partial \bar{w}_{B}^{S *} / \partial \gamma=\left(28-\gamma^{4}-26 \gamma^{3}+83 \gamma^{2}-76 \gamma\right) \beta / 2 B^{2}>0$.
} 
ii) overall welfare, such as output (employment) and union utility, is always higher without managerial delegation (or PP contracts). In addition, when managerial delegation applies, social welfare, output and union utility are only higher under sales delegation than relative profit delegation when the degree of substitutability between products is sufficiently high.

Given the previous analyses and discussions, Result 3 is quite intuitive. Note that, when competition is in terms of price, sales (hence employment) are always penalized under $\mathrm{S}$ contracts. Additionally, the wage chosen by the central union is always lower than the wage chosen under RP (and PP) contracts. This explains why (when products are not strict substitutes), union utility and overall welfare are lower yet profits are higher under sales delegation than RP contracts. However, when products tend to become perfect substitutes $(\gamma \rightarrow 1)$, then: i) the bonus weight under $\mathrm{S}$ contracts tends to zero, hence sales are no longer penalized; and ii) the negative wage differential that applies under sales delegation with respect to other schemes tends to vanish. Thus, when $\gamma$ is sufficiently large, the previous findings are reversed. ${ }^{21}$

\footnotetext{
${ }^{21}$ Similar to the Cournot competition (and product differentiation) case, also under price competition there is the possibility that all agents involved will prefer the same "delegation solution" although, with respect to the Cournot case, this applies to a smaller range of product differentiation. Indeed, under price competition, all agents prefer PP contracts/no-delegation solution (hence, shifting to this case is Pareto improving) only when products are nearly perfect complements $(\gamma<-0.936)$.
} 


\section{Conclusion}

We have studied how, in a duopoly product market, managerial delegation schemes interact with the wage decisions taken by a central (industry-wide) union in the labor market. We have analyzed a model where, at the first stage, the owners optimally choose a delegation contract for their managers, which may be a sales delegation or relative profit type. In the second stage, the union fixes the wages for all (non-managerial) workers in the industry; and finally, in the third stage, managers compete in the product market.

Interestingly, the results proved to be more variegated compared to those obtained in the managerial delegation literature, where firm production costs are assumed to be exogenously given. In fact, the literature has shown that in equilibrium owners are always better off (i.e., profits are higher) under relative profit delegation and the reverse holds true for consumers and society as a whole (i.e., consumer surplus and social welfare are higher under sales delegation). In contrast, we have highlighted that when production costs are endogenous (i.e., the wage is set by a central union) both firms' profitability and welfare outcomes may be higher under both sales delegation and relative profit delegation. This depends on various factors such as the degree of product differentiation and the competition regime in the product market. 


\section{Appendix}

\section{A.1 Derivation of equilibrium outcomes in Section 4.1 (product differentiation and quantity competition)}

\section{PP contracts:}

Under PP contracts (or in the case without delegation), product differentiation and quantity competition, in stage 3 , firm $i$ maximizes its profits taking (28) into account. In such a case, the corresponding equations for (7) and (8) in Section 2.2 (i.e., for homogeneous products) are, respectively:

(A1)

$$
q_{i}\left(q_{j}, w\right)=\frac{1-\gamma q_{j}-w}{2}
$$

$$
q_{i}(w)=\frac{1-w}{2+\gamma} .
$$

By substituting for (A2) in (4) and maximizing with respect to $w$, we get the equilibrium wage. Finally, by substituting back, we derive the other equilibrium outcomes as defined, for this case, in Section 4.1.

\section{$S$ contracts:}

Under S contracts, product differentiation and quantity competition, in stage 3 , manager $i$ maximizes $u_{i}=\pi_{i}+b_{i} q_{i}$ taking (28) into account. In this case, the corresponding equations for steps (12) to (16) in Section 3.1 with homogeneous products become, respectively: 
(A3)

$$
q_{i}\left(q_{j}, w, b_{i}\right)=\frac{1-\gamma q_{j}-w+b_{i}}{2}
$$

$$
q_{i}\left(w, b_{i}, b_{j}\right)=\frac{(2-\gamma)(1-w)+2 b_{i}-\gamma b_{j}}{4-\gamma^{2}}
$$

$$
w\left(b_{i}, b_{j}\right)=\frac{2 \alpha+b_{i}+b_{j}}{4}
$$

$$
\pi_{i}\left(b_{i}, b_{j}\right)=\frac{\left[(4-2 \gamma) \beta+(6+\gamma) b_{i}-(2+3 \gamma) b_{j}\right]\left[(4-2 \gamma) \beta+\left(4 \gamma^{2}+\gamma-10\right) b_{i}-(2+3 \gamma) b_{j}\right]}{16\left(4-\gamma^{2}\right)^{2}}
$$

$$
b_{i}\left(b_{j}\right)=\frac{\left(4 \gamma^{3}-6 \gamma^{2}-8 \gamma+8\right) \beta-\left(4-6 \gamma^{3}-7 \gamma^{2}+4 \gamma\right) b_{j}}{4 \gamma^{3}+25 \gamma^{2}-4 \gamma-60}
$$

from which, taking the (symmetric) reaction function of owner $j$ into account, we obtain the equilibrium bonus weight as defined in (30). Then, by substituting back we get the other equilibrium outcomes.

\section{RP contracts:}

Under RP contracts, product differentiation and quantity competition, in stage 3, manager $i$ maximizes $u_{i}=\pi_{i}-b_{i} \pi_{j}$ taking (28) into account. In this case, the corresponding equations for (20) and (21) in Section 3.2 are, respectively:

$$
\begin{aligned}
& q_{i}\left(q_{j}, w, b_{i}\right)=\frac{1-\gamma q_{j}\left(1-b_{i}\right)-w}{2} \\
& q_{i}\left(w, b_{i}, b_{j}\right)=\frac{(1-w)\left[2-\gamma\left(1-b_{i}\right)\right]}{4-\gamma^{2}\left(1-b_{i}\right)\left(1-b_{j}\right)} .
\end{aligned}
$$


In the second stage, after substitution of (A9) and the corresponding expression for $j$, the union unilaterally chooses a uniform wage by maximizing (4), which leads to:

$$
\text { (A10) } \quad w=\frac{1}{2} \alpha
$$

Since the wage decision by the union only depends on the reservation wage (i.e. such a decision is exogenous from the owner's viewpoint), our analysis of the owner's decision with regard to the optimal bonus weight clearly parallels Miller and Pazgal (2002), and gives the same result (Miller and Pazgal, 2002, Proposition 11; see also Manasakis et al., 2010, Appendix A.2). By substituting (A9) and (A10) in firm $i$ 's profit equation and maximizing with respect to $b_{i}$, we get:

$$
\text { (A11) } \quad b_{i}\left(b_{j}\right)=\frac{\gamma(2-\gamma)\left(1-b_{j}\right)}{4-\gamma(2+\gamma)\left(1-b_{j}\right)} \text {. }
$$

Taking $b_{i}=b_{j}$ into account, we solve (A11) with respect to $b_{i} \in(-1,1)$, which leads to:

$$
\text { (A12) } \quad b_{i}=\frac{\gamma}{2+\gamma} \text {. }
$$

Substituting back, we derive the other equilibrium outcomes as defined, for this case, in Section 4.1 . 


\section{A.2 Derivation of equilibrium outcomes in Section 4.2 (price competition)}

\section{PP contracts:}

Under PP contracts/no-delegation case and price competition, in stage 3, firm $i$ maximizes its profits with respect to its own price taking (36) into account. This leads to the following:

(A13)

$$
p_{i}\left(p_{j}, w\right)=\frac{1-\gamma\left(1-p_{j}\right)+w}{2}
$$

$$
p_{i}(w)=\frac{1-\gamma+w}{2-\gamma}
$$

$$
q_{i}(w)=\frac{1-w}{(1+\gamma)(2-\gamma)}
$$

By substituting for (A15) in (4) and maximizing with respect to $w$, we get the equilibrium wage as defined in (37). Finally, by substituting back we derive the other equilibrium outcomes for this case.

\section{$S$ contracts:}

Under S contracts and price competition, in stage 3, manager $i$ maximizes $u_{i}=\pi_{i}+b_{i} q_{i}$ with respect to $p_{i}$ taking (36) into account. This leads to the following:

$$
\begin{aligned}
& p_{i}\left(p_{j}, w, b_{i}\right)=\frac{1-\gamma\left(1-p_{j}\right)+w-b_{i}}{2} \\
& p_{i}\left(w, b_{i}, b_{j}\right)=\frac{(2+\gamma) w+2\left(1-b_{i}\right)-\gamma b_{j}-\gamma(1+\gamma)}{4-\gamma^{2}}
\end{aligned}
$$


(A18)

$$
q_{i}\left(w, b_{i}, b_{j}\right)=\frac{\left(\gamma^{2}+\gamma-2\right) w-\gamma b_{i}+\left(2-\gamma^{2}\right)\left(1+b_{j}\right)}{\left(1-\gamma^{2}\right)\left(4-\gamma^{2}\right)}
$$

In stage 2, the union maximizes (4) taking (A18) and the corresponding for $j$ into account, which leads to:

(A19) $\quad w\left(b_{i}, b_{j}\right)=\frac{2 \alpha+b_{i}+b_{j}}{4}$.

By substituting for (A17), (A18) and (A19) in firm i’s profit equation, we obtain:

(A20)

$\pi_{i}\left(b_{i}, b_{j}\right)=\frac{\left[\left(4-2 \gamma^{2}-2 \gamma\right) \beta+\left(6-\gamma^{2}+\gamma\right) b_{i}-\left(2-\gamma^{2}+3 \gamma\right) b_{j}\right]\left[\left(4-2 \gamma^{2}-2 \gamma\right) \beta-\left(10-\gamma^{2}-\gamma\right) b_{i}-\left(2-\gamma^{2}+3 \gamma\right) b_{j}\right]}{16\left(1-\gamma^{2}\right)\left(4-\gamma^{2}\right)^{2}}$

and maximizing (at stage 1) with respect to $b_{i}$, we get the following reaction function for owner $i$ :

(A21)

$$
b_{i}\left(b_{j}\right)=\frac{\left[\left(4-2 \gamma^{2}-2 \gamma\right) \beta-\left(2-\gamma^{2}+3 \gamma\right) b_{j}\right]\left(\gamma^{2}-\gamma+2\right)}{\left(3 \gamma^{2}-\gamma-6\right)\left(10-\gamma^{2}-\gamma\right)}
$$

Taking the (symmetric) reaction function of owner $j$ into account, we get the equilibrium bonus weight as defined in (38). Finally, by substituting back we get the other equilibrium outcomes. 


\section{RP contracts:}

Under RP contracts and price competition, in stage 3, manager $i$ maximizes $u_{i}=\pi_{i}-b_{i} \pi_{j}$ with respect to $p_{i}$ taking (36) into account. This leads to the following:

(A22)

$$
p_{i}\left(p_{j}, w, b_{i}\right)=\frac{1-\gamma\left[1-p_{j}\left(1-b_{i}\right)-w b_{i}\right]+w}{2}
$$

$$
p_{i}\left(w, b_{i}, b_{j}\right)=\frac{2+(2+\gamma) w-b_{i}[\gamma(1-w-\gamma)]+b_{j} \gamma^{2} w\left(1-b_{i}\right)-\gamma(1+\gamma)}{4-\gamma^{2}\left(1-b_{i}\right)\left(1-b_{j}\right)}
$$

$$
q_{i}\left(w, b_{i}, b_{j}\right)=\frac{(1-w)\left[2+\gamma+\gamma b_{j}\left(1+\gamma-\gamma b_{i}\right)\right]}{(1+\gamma)\left[4-\gamma^{2}\left(1-b_{i}\right)\left(1-b_{j}\right)\right]} .
$$

After substitution of (A24) and the corresponding expression for $j$, the union unilaterally chooses a uniform wage at the second stage of the game by maximizing (4), which leads to:

(A25)

$$
w=\frac{1}{2} \alpha
$$

Similar to the discussion in Section A.1 regarding this case, since the wage decision is exogenous from the owners' viewpoint, our analysis regarding the optimal bonus weight by owners agrees with Miller and Pazgal (2002), and gives the same result (Miller and Pazgal, 2002, Proposition 9). By substituting for (A24) and (A25) in firm i’s profit equation and maximizing with respect to $b_{i}$, we get: 
(A26) $\quad b_{i}\left(b_{j}\right)=\frac{\gamma(2+\gamma)\left(1-b_{j}\right)}{4+\gamma(2-\gamma)\left(1-b_{j}\right)}$

and, taking $b_{i}=b_{j}$ into account, we get only one solution for $b_{i} \in(-1,1)$ :

(A27)

$$
b_{i}=\frac{\gamma}{\gamma-2}
$$

Substituting back, we derive the other equilibrium outcomes as defined, for this case, in Section 4.2 . 


\section{References}

Aggarwal RK, Samwick AA. 1999. Executive compensation, strategic competition, and relative performance evaluation: Theory and evidence. Journal of Finance 54: 1999-2043.

Baker GP, Jensen MC, Murphy KJ. 1988. Compensation and incentives: practice vs. theory. Journal of Finance 43: 593-616.

Barro J, Barro RJ. 1990. Pay, performance, and turnover of bank CEOs. Journal of Labor Economics 8: 448-481.

Baumol W. 1958. On the theory of oligopoly. Economica 25: 187-198.

Belman D. 1988. Concentration, unionism, and labor earnings: a sample selection approach. Review of Economics and Statistics 70: 391-397.

Berle AA, Means GC. 1932. The Modern Corporation and Private Property. Harcourt, Brace and World: New York.

Blanchflower D. 1986. Wages and concentration in British manufacturing. Applied Economics 18, 1025-1038.

Booth AL. 1995. The Economics of the Trade Union. Cambridge University Press: Cambridge.

Brekke KR. 2004. Competition or coordination in hospital markets with unionised labour. International Journal of Health Care Finance and Economics 4: 65-89.

Bughin J. 1995. Unions and strategic managerial incentives. Economics Letters 47: 95-100. 
Calmfors L, Driffill J. 1988. Centralisation and wage bargaining. Economic Policy 6: 13-61.

Chatterjee I, Saha B. 2011. Bilateral delegation, wage bargaining and managerial incentives: implications for efficiency and distribution. University of East Anglia AEP Discussion Papers in Economics 2011/28, University of East Anglia, Norwich, UK.

Correa-López M. 2007. Price and quantity competition in a differentiated duopoly with upstream suppliers. Journal of Economics \& Management Strategy 169: 469-505.

Correa-López M, Naylor RA. 2004. The Cournot-Bertrand profit differential: a reversal result in a differentiated duopoly with wage bargaining. European Economic Review 48: 681-696.

Dhillon A, Petrakis E. 2002. A generalised wage rigidity result. International Journal of Industrial Organization 20, 285-311.

Dickens WT, Katz,LF. 1987. Inter-industry wage differences and theories of wage determination. NBER Working Paper No. 2271.

Dowrick SJ. 1989. Union-oligopoly bargaining. Economic Journal 99: 1123-1142.

Dowrick S, Spencer BJ. 1994. Union attitudes to labor-saving innovation: When are unions luddites? Journal of Labor Economics 12: 316-344

Fanti L, Meccheri N. 2013. Managerial delegation under alternative unionization structures. Labour 27: $38-57$.

Fershtman C. 1985. Managerial incentives as a strategic variable in duopolistic environment. International Journal of Industrial Organization 3: 245-253. 
Fershtman C, Judd K. 1987. Equilibrium incentives in oligopoly. American Economic Review 77: 927-940.

Flanagan RJ. 1999. Macroeconomic performance and collective bargaining: an international perspective. Journal of Economic Literature 37: 1150-1175.

Freeman R. 1988. Labour markets. Economic Policy 6: 63-80.

Gibbons R, Murphy KJ. 1990. Relative performance evaluation for chief executive officers. Industrial and Labor Relations Review 43: 30S-51S.

Janakiraman S, Lambert R, Larcker D. 1992. An empirical investigation of the relative performance evaluation hypothesis. Journal of Accounting Research 30: 53-69.

Jansen T, van Lier A, van Witteloostuijn A. 2007. A note on strategic delegation: the market share case. International Journal of Industrial Organization 25: 531-539.

Jansen T, van Lier A, van Witteloostuijn A. 2009. On the impact of managerial bonus systems on firm profit and market competition: the cases of pure profit, sales, market share and relative profits compared. Managerial and Decision Economics 30: 141-153.

Jansen T, van Lier A, van Witteloostuijn A. 2012. Managerial bonus systems in a differentiated duopoly: a comment. Managerial and Decision Economics 33: 61-70.

Jensen MC, Murphy KJ. 1990. Performance pay and top management incentives. Journal of Political Economy 98: 225-264. 
Horn H, Wolinsky A. (1988a). Worker substitutability and patterns of unionisation. Economic Journal 98: 484-497.

Horn H, Wolinsky A. (1988b). Bilateral monopolies and incentives for merger. RAND Journal of Economics 19: 408-419.

Lambert RA, Larcker DF, Weigelt K. 1991. How sensitive is executive compensation to organizational size. Strategic Management Journal 12: 395-402.

Layard R, Nickell S, 1999. Labor market institutions and economic performance. In: O.C. Ashenfelter and D. Card (Eds.), Handbook of Labor Economics, vol. 3, North Holland: Amsterdam.

Liao P-C. 2010. Strategic delegation under unionised duopoly: who will bargain with unions? Australian Economic Papers 49: 276-288.

Lommerud KE, Straume OR, Sørgard L. 2005. Downstream merger with upstream market power. European Economic Review 49: 717-743.

Manasakis C, Mitrokostas E, Petrakis E. 2010. Endogenous managerial incentive contracts in a differentiated duopoly, with and without commitment. Managerial and Decision Economics 31: $531-543$.

Mauleon A, Vannetelbosch VJ. 2006. Strategic union delegation and incentives for merger. Applied Economics Letters 13: 1-5.

Mezzetti C, Dinopoulos E. 1991. Domestic unionization and import competition. Journal of International Economics 31: 79-100. 
Miller N, Pazgal A. 2001. The equivalence of price and quantity competition with delegation. RAND Journal of Economics 32: 284-301.

Miller N, Pazgal A. 2002. Relative performance as a strategic commitment mechanism. Managerial and Decision Economics 23: 51-68.

Naylor RA. 1999. Union wage strategies and international trade. Economic Journal 109: 102-125.

Pencavel JH. 1984. The trade-off between wages and employment in trade union objectives. Quarterly Journal of Economics 99: 215-231.

Pencavel JH. 1985. Wages and employment under trade unionism: micro-economic models and macroeconomic applications. Scandinavian Journal of Economics 87: 197-225.

Petrakis E, Vlassis M. 2000. Endogenous scope of bargaining in a union-oligopoly model: when will firms and unions bargain over employment? Labour Economics 7: 261-281.

Rees A. 1977. The Economics of Trade Unions. University of Chicago Press: Chicago.

Salas-Fumás V. 1992. Relative performance evaluation of management: the effects on industrial competition and risk sharing. International Journal of Industrial Organization 10: 473-489.

Segal M. 1964. The relation between union wage impact and market structure. Quarterly Journal of Economics 78, 96-114.

Singh N, Vives X. 1984. Price and quantity competition in a differentiated duopoly. RAND Journal of Economics 15: 546-554. 
Sklivas S. 1987. The strategic choice of managerial incentives. RAND Journal of Economics 18: $452-458$.

Spulber D. 1989. Regulation and Markets. MIT Press: Cambridge (MA).

Szymanski S. 1994. Strategic delegation with endogenous costs. a duopoly with wage bargaining. International Journal of Industrial Organization 12: 105-116.

Symeonidis G. 2010. Downstream merger and welfare in a bilateral oligopoly. International Journal of Industrial Organization 28: 230-243.

van Witteloostuijn A, Jansen T, van Lier A. 2007. Bargaining over managerial contracts in delegation games: managerial power, contract disclosure and cartel behavior. Managerial and Decision Economics 28: 897-904.

Vickers J. 1985. Delegation and the theory of the firm. Economic Journal 95: 138-147.

Wallerstein M. 1999. Wage-setting institutions and pay inequality in advanced industrial societies. American Journal of Political Science 43, 649-680.

Weiss LW. 1966. Concentration and labor earnings. American Economic Review 56, 96-117. 